\title{
Gadflies Biting Science Communication: Engagement, Tricksters, and Ambivalence Online
}

Science Communication 2017, Vol. 39(5) 673-684

(C) The Author(s) 2017

Reprints and permissions: sagepub.com/journalsPermissions.nav DOI: $10.1177 / 1075547017736068$ journals.sagepub.com/home/scx

(S)AGE

\section{Jonathan Mendel' and Hauke Riesch ${ }^{2}$}

\begin{abstract}
Large-scale online science communication and engagement projects can assume an overly ordered and sterile type of online public space or civil society. Against this, the article offers a vision of more carnivalesque spaces for online science communication and engagement. Participants in these spaces taking the role of tricksters disrupting the status quo might offer new opportunities for engagement, play, and politics online: the online public sphere for discussing science is broken, and we should look for ways to break it better. Acknowledging the limitations of a trickster-like approach, we also consider the ambivalence inherent in carnivalesque play as engagement practice.
\end{abstract}

\section{Keywords}

blogging, Internet, tricksters, trolling, ambivalence, agenda setting

The state is like a great and noble steed who is tardy in his motions owing to his very size, and requires to be stirred into life. I am that gadfly which God has given the state and all day long and in all places am always fastening upon you, arousing and persuading and reproaching you.

—Socrates, from Plato's (n.d.) Apology

\footnotetext{
'University of Dundee, Dundee, UK

${ }^{2}$ Brunel University, London, UK

\section{Corresponding Author:}

Jonathan Mendel, Geography, School of Social Sciences, University of Dundee, Dundee DDI $4 \mathrm{HN}, \mathrm{UK}$.

Email: j.m.mendel@dundee.ac.uk
} 
[Socrates] is widely considered to be the most irritating man in history.

-Encyclopedia Dramatica

Much "mainstream" science communication, and discussions of the relationship between science and civil society, assume that a loosely Habermasian public sphere and deliberative democracy is an appropriate goal. This has remained the case with influential work on online science communication. For example, Anderson, Brossard, Scheufele, Xenos, and Ladwig (2014) view blog comments as a "space for deliberation" and argue that they do not serve this goal well. We do acknowledge that incivility, abuse, and trolling play a role in the frequent failure of online comment spaces to provide a good public sphere for deliberation (around science or other topics) and in the frequent collapse of aspects of online civil society. However, we will also argue that one should not simply assume that "bad" tricksters are disrupting "good" online spaces for deliberation: many large-scale online science communication projects are themselves broken from the start and construct unengaging online public spheres (see, e.g., Mendel, 2014; Nisbet \& Scheufele, 2009).

Science communication online can fulfil a number of roles. Some of the goals of science communication might be related to deliberation or participatory democracy. However, in this commentary we challenge any deterministic claim that online science communication should only be this. "Rational" spaces for participatory democracy are not the only-and, we would suggest, often not the most effective- means of engagement through online science communication. When writers and researchers criticize online spaces for discussing science because of their noise and arguments and fights this sometimes rather misses the point: in the case of some lively, active spaces this is like going to a carnival and complaining that it is too loud and disordered to allow for "rational" debate. Instead, we will argue for a reconceptualization of what online public spaces could be and a renewed sense of purpose for online science communication.

In order to offer alternatives, we will turn to the trickster archetype (BassilMorozow, 2015) as a far more playful possibility. We will use Deleuze and Guattari's (1988) work around pragmatics in order to think through how science communication might be put to use, and draw on Phillips and Milner's (2017) work to reflect on ambivalent aspects of these online activities. We will use the trickster as a concept through which we can understand, theorize, and advance the way these disruptions are being performed.

This commentary draws on our work on the Science: So What? So Everything engagement campaign, which the U.K. government's then Department for Innovation, Universities and Skills intended to stir public 
enthusiasm for STEM subjects (Mendel, 2014; Mendel \& Riesch, 2015; Riesch \& Mendel, 2014). We looked at Science: So What, and some responses to it, and contrasted this with other types of online engagement (see Mendel, 2014).

This commentary has also sprung out of our participation in, engagement with, and research about the badscience blogging network (Mendel \& Riesch, 2015; Riesch \& Mendel, 2014). ${ }^{1}$ We were struck by how effectively this network was able to engage with a substantial audience through using humor, playfulness, and a less hierarchical networked structure. The badscience bloggers campaigned on various issues but, rather than aiming solely at "rational" deliberation, more often echoed the Nietzschean, Dionysian impulse that Coleman (2014, p. 532) finds in Anonymous: "Not by wrath does one kill but by laughter." The badscience bloggers' challenge to what is seen as bad science often came with jokes and mockery rather than with the more serious approach found in much science communication (and in much of the broader skeptic community; Riesch \& Mendel, 2015). This commentary has been informed — or, perhaps, seduced — by trickster-like aspects of this blogging network as we try to conceptualize how this approach can potentially shake up our notions of what good science communication could be. As such, this work is influenced by the type of (auto)ethnographic "remix" that Phillips and Milner (2017, p. 19) describe: as scholars and people, these are "texts and traditions that we ... have personally engaged with and enjoyed."

\section{The (Online) Public Sphere Is Broken, So Let's Break It Better}

Rather than online and social media discussions of science being a deviation from an ideal preexisting space for engagement, we instead propose to think in terms of different types of problems, limitations, and exclusions. Rather than thinking about (very real and harmful) problems such as abuse and trolling breaking online spaces for engagement with science, we would view these spaces as already broken in many ways. The question then becomes one of how they can be broken better.

The Science: So What? So Everything campaign was a science communication campaign from the United Kingdom's then Department for Innovation, Universities and Skills that

aimed to get readers to "look again at science: what is it doing for us already? How is it going to drive us to a better future? Why not take a look around, and see how science is touching you. (Mendel, 2014, p. 57) 
It particularly aimed to inspire young people to pursue science-related careers (Mendel, 2014). This was a substantial campaign, backed by a $£ 1$ millionplus budget and drawing on high-profile support including that of the United Kingdom's then prime minister. The campaign achieved significant coverage in "mainstream" media; for example, looking at a report on future jobs,

Kindred-the Public Relations (PR) agency behind the campaign-assessed impact by noting that the report achieved " 178 pieces of coverage across national, regional, consumer and online media. . . A combined OTS [opportunities to see] of $60,985,597$. . . An AEV [Advertising Equivalent Value] of $£ 2,248,866$. (Mendel, 2014, p. 58)

However, some online aspects of the campaign were rather more limited. The campaign generated under 8,000 website hits per day with its launch publicity (which was itself a significant increase on prior to that); this is low for a campaign at this scale (Holmes \& Mendel, 2010). While there was some online discussion with the public on Twitter early on, the type of online discussion about why science matters in our lives that might have been hoped for did not emerge, and there certainly was not the development of a Habermasian public sphere for "rational" debate. Where further online discussion did ultimately emerge, this was more focused around criticizing aspects of the Science: So What campaign-such as a weak report on future jobs (see Mendel, 2014).

Engagement with Science: So What (which included these authors) became livelier as it also became more conflictual, louder, and more playful. We saw that "social media responses were able to offer relatively fast and in-depth challenges to seemingly hasty claims in the report: for example, to over-optimistic claims about nano-technology and medicine" (Mendel, 2014, p. 59). An ambivalent type of play was important here; for example, the blogger James Hayton (2010) points out that he "just wanted to find where the idea of sub-atomic machines had come from, poke fun at it, and go about my business"; however, this led him into a more substantive critique. Mendel and Holmes (2010) blogged the lack of "participatory joy" in Science: So What and argued instead for the need to find "new ways to understand, engage with and change the world." Rather than moving toward any "rational" consensus, the fun of joking about, mocking, and arguing with a large science communication campaign was more engaging than the online aspects of the campaign itself. $^{2}$ Multiple interlocutors (including these authors), combining this drive for play and for poking the campaign with discussion of some of the more substantive issues that their play drew them into, helped form a swarm of ambivalent gadflies. 
Such play and swarms of gadflies have been seen in other science-related contexts, too. For example, one might note the emergence of the \#distractlinglysexy Twitter hashtag in response to the senior scientist Tim Hunt's comments about gender in the lab (see Morello, 2015). Women working in science tweeted selfies and other comments, in order to humorously challenge the idea that they were a distraction in the lab: disrupting conventional scientific hierarchies for progressive political purposes. More ambivalently, one might note the response to the United Kingdom's Natural Environment Research Council's decision to allow the public to name their new boat: much discussion, joking, and arguing led to a public vote to name it Boaty McBoatface, and followed Natural Environment Research Council's decision not to use this name for the boat (Phillips \& Milner, 2017, pp. 164-169).

While loud, playful online discussions of science might make some feel melancholic about the loss of imagined science-related online spaces for an idealized participatory democracy or deliberation, we would question to what extent these spaces actually existed in the first place. It is important to remember both where science communication/Public Understanding of Science (PUS) have come from and where we currently are. For all the rhetoric about a move from PUS to PEST (public engagement with science and technology, rather than public understanding), there is still frustration that the rhetoric of open participatory engagement rarely matches with reality (Irwin, 2014). Part of the problem here is that whatever idealized engagement is envisaged, the spaces - online or offline - in which it happens are frequently set up, controlled, managed, and/or owned by groups or individuals. These may then have limiting and, often, overly prescriptive ideas of what constitutes permissible discourse. Online engagement with science may sometimes be noisy or even uncivil and may breach some ideas of permissible discourse, but this does not just take us away from an idealized type of engagement that existed prior to the noise of social media; instead, this is a move from one imperfect situation to another.

We would emphasize that some aspects of online discussions of science are mostly or entirely negative and should be robustly challenged - for example, the fact that women writing about science online often face threats of sexual violence is clearly extremely negative (see Mendel \& Riesch, 2015; Riesch \& Mendel, 2014, for further discussion of this). The use of an (intended) humorous manner does not make online harassment or threats of violence any less objectionable and may in some cases amplify the harm caused.

\section{Tricksters: Trolling Science Communication?}

In Bassil-Morozow's (2015) words, the "trickster" is a "psycho-anthropological" concept (an "archetype" for Jung) that appears as a recurrent figure in 
mythology. Frequently mentioned examples are the Coyote in Native American mythology or Anansi in West African mythology. Tricksters appear often in creation myths where they provide often paradoxical and whimsical explanations of why the world is as it is (Weaver \& Mora, 2016), but they also appear more widely in fairy tales, or more modern narratives such as movies and novels. Trickster narratives share themes and motifs that BassilMorozow summarizes among others as the trickster's liminality and boundary breaking behavior, licentiousness, shape-shifting, and scatological references. Tricksters are often morally ambiguous, acting out of their own interests but also often (but not necessarily) affecting the world positively as a result. Tricksters, as the name suggests, use tricks, deception, and subversion in order to advance their goals.

Trickster discourse, as Weaver and Mora (2016, p. 480) describe it, "is that which can affect the social through unorthodox and possibly subversive means." This leads Weaver, Mora, and the contributors to their special issue to explore tricksters in contemporary humor studies. The trickster can also be used as an analytical tool to make sense of online trolling and its social/political positioning, for example by Phillips (2015). Phillips (2015, pp. 126-128) highlights the philosophical appeal of Socrates to certain (anti)social groupings of trolls. As she notes, Encyclopedia Dramatica (a famous "trolling" text) quotes Socrates's argument that "I am that gadfly which God has attached to the state, and all day long and in all places am always fastening upon you, arousing and persuading and reproaching you" (Phillips, 2015, p. 126). Encyclopedia Dramatica further argues that Socrates is "widely considered to be the most irritating man in history" (Phillips, 2015, p. 126). We observed that those acting as tricksters or trolls offering creative and critical responses to some "mainstream" science communication projects were not always especially well-received by the project teams - and, indeed, may well have been frustrating for them. For example, the Science: So What? project attracted numerous critical responses from science bloggers and others and did not initially take all these well (Holmes \& Mendel, 2010; Mendel, 2014). It is quite possible that the Science: So What? team sometimes felt themselves to be beset by gadflies when facing critical responses from bloggers (including one of these authors). However, we would argue that this is precisely what some "mainstream" science communication projects need-to be beset by biting, irritating swarms of gadflies, in order to challenge projects that can be overcentralized, unwieldy, dull, and expensive. It is in the spirit of such a swarm of gadflies - and in an ambivalent celebration of irritating, stinging, itching approaches to the status quo - that we present this article.

The trickster concept offers a way to understand the value of these gadflies. Though most tricksters, trolls, and commentators of course will not be 
as insightful as Socrates, their function as the liminal, outsider, and often impolite disruptors of conventional science communication discourses can serve the useful purpose of shaking things up, disrupting complacency and revealing unimagined shortcomings, not necessarily through any clear moral purpose behind the criticism, but for the enjoyment of making it. For Massumi (1988, p. xii), in Deleuze and Guattari's (1988) work a concept is a brick that might "be used to build the courthouse of reason [or] thrown through the window." Science communication and PUS are rich sources of concepts. Drawing on Deleuze and Guattari's (1988) work, we would hope to provoke more use of science communication concepts to break things, trickster-like, as well as building new and different spaces of science communication.

\section{Ambivalence}

Writing about a range of "weird" online behaviors, Phillips and Milner (2017, p. 10) emphasize the importance of ambivalence, "implying tension, and often fraught tension, between opposites." Looking at trickster-like play around (professed) fandom for mass murderers, they suggest that

[e]ven playful fawning over mass shooters could be seen from several co-occurring vantage points, from excessive attachment to excessive dissociation to a pointed satire of ... news coverage [or] Maybe the people who post Columbine sweetheart photos are just assh*les. Maybe all of the above.

(Phillips \& Milner, 2017, p. 11)

Maybe some of those writing playful critiques of and jokes about Science: So What were involved in a critique of the limitations of government science communication (or broader government practices); maybe they were wanting to point and laugh at what seemed to be a weak campaign; maybe it was a social thing; maybe it was a swarm of gadflies biting at the campaign in order to spur it on to different things; maybe they (or we) were something else. . . . Or maybe all of the above. We will try to retain some of this ambivalence below, rather than falling into any complete celebration or rejection of the role of tricksters in online science communication.

\section{Biting Science Communication: Beyond the Trickster Archetype}

While important, the archetype of the trickster is not, in itself, sufficient. Indeed, Coleman $(2014$, p. 77$)$ acknowledges that the trickster is "one heuristic - certainly not the only or primary one" for understanding trolls 
and Anonymous. Žižek (2012) offers an important challenge to the perceived role of the trickster today,

With the full deployment of capitalism ... it is the predominant "normal" life itself that ... gets carnivalised ... it is the critique of capitalism, from a stable ethical position, that more and more appears today as an exception. (p. 189)

As Phillips (2015, p. 11) argues, online tricksters such as "trolls" can thus be viewed as "par for the mainstream cultural course" instead of something that lies outside of mainstream culture. Rather than simply accepting the "mainstream cultural course," we would draw again on hopes of "science for the people" and the "radicalization of science" (Rose \& Rose, 1972).

We should thus be ambivalent about tricksters: rather than helping to break online spaces better, there is a real risk that trickster-type approaches might be too easily absorbed into - or amplify many negative aspects of - the status quo. We should also remain ambivalent about our own use of the word "troll": we acknowledge the risk that "the term tends to minimize the negative effects of the worst kinds of online behaviors" (Phillips \& Milner, 2017, p. 8). While swarms of biting gadflies might help achieve change, within or beyond online discussions of science, they can also be destructive in extremely regressive ways.

While we do not accept that a broadly Habermasian public sphere is either a desirable or actually existing space for online science communication, we would also argue for a move beyond "just" relying on the references to tricksters that are often used to capture more playful online discourses. Looking at different strategies will help think about how this might play out. Here, we would return again to the approach suggested by Phillips and Milner (2017, p. 19) where we are both studying and engaging with, and enjoying, some of the behaviors we discuss: aiming for work that "coolly stands apart from and defiantly inhabits the worlds it describes."

To begin with, one might build on carnivalesque challenges to big, centralized online science communication projects in order that these networks of tricksters can become part of a long-term change in the status quo. Taking the trickster seriously might let us challenge some of the problems of official online science communication and the types of civil society associated with it. However, this beginning risks just making the injustices of the status quo more tolerable - allowing some new types of enjoyment to be had while remaining within the constraints of the current system. In his influential analysis of Renaissance-era carnivals, Bakhtin (1984) posited just this as one of the institutional effects of carnival: that it allowed people to let off steam and thus reinforce, rather than challenge, hierarchies. A second type of challenge, 
then, would entail a fuller move beyond the figure of the trickster - and, instead, seeking stable ethical and political positions from which to criticize large, government- or corporation-led science communication projects. If, as suggested above, concepts of science, communication, and engagement are bricks that can "be used to build the courthouse of reason [or] thrown through the window" (Massumi, 1988, p. xii) then it is high time to hear the sound of breaking glass.

The challenges that tricksters pose to mainstream science communication can be funny and rewarding and engaging in themselves; they might also facilitate politically powerful moves beyond the trickster figure; or it might just be people being uncivil for the sake of it. These challenges can also be all of the above.

\section{Conclusions}

Science communication now takes place in a context where trolling and ambivalence are intimately linked to mainstream culture (Phillips, 2015; Phillips \& Milner, 2017). We would argue that this is also-maybe particularly - the case in online science communication and engagement. In order to build fruitful spaces for engagement, we should look to take advantage of the interactive potential of (somewhat) new technologies and spaces and resist the tendency for our work as scholars to be used to further close off or "clean up" online spaces of science communication and engagement (see Walsh, 2015). To do so, it is important to move beyond a focus on orderly online spaces for deliberation: we should look instead at opportunities to play in and to further break these already broken spaces. More carnivalesque approaches might offer much more enjoyable and fruitful spaces in which to participate; we might also move beyond such approaches in order to build stable ethical and political positions from which to further disrupt the status quo.

To go from our discussion of tricksters to argue for radical moves to shatter the status quo in science communication is, admittedly, something of a stretch. This article has sprung from our own participation in online networks such as badscience, discussing, arguing, and joking about science (Mendel \& Riesch, 2015; Riesch \& Mendel, 2014), and we have, to an extent, been infected ourselves by this trickster approach. We certainly would not claim that there is any deterministic path to policy change and political change here. However, by drawing on and moving beyond the trickster archetype there might be a lot of fun to be had in building carnivalesque spaces for public engagement; moving beyond this might open up opportunities for shattering the status quo and (re)building a radical science communication that includes the whimsical and carnivalesque alongside earnest political contributions. To draw again on 
Phillips and Milner's (2017) work, we will end on a note that echoes the ambivalent Internet this work has sprung from: this article could be read as a radical challenge to "mainstream" science communication; it could be a joke; we might be terrible scholars and horrible people. Or, maybe, all of the above.

\section{Acknowledgments}

We are grateful for the helpful comments on this article from Linda Billings, Sarah Rachael Davies, and Susanna Priest. Simon Weaver helped us with our work on tricksters. We have benefited from valuable feedback on a previous version of this article received from participants at a University of Copenhagen event on STS approaches to science communication (particularly Felicity Mellor's detailed comments) and when presenting it to Dundee University's Society Research Group; Data \& Society Research Institute's Databite No. 99 event helped inspire our discussion of ambivalence. We are particularly grateful to the badscience bloggers who participated in work related to this and discussed this related work with us.

\section{Declaration of Conflicting Interests}

The author(s) declared no potential conflicts of interest with respect to the research, authorship, and/or publication of this article.

\section{Funding}

The author(s) disclosed receipt of the following financial support for the research, authorship, and/or publication of this article: Jonathan Mendel benefited from support funding allocated through the School of Social Sciences Research and Knowledge Exchange Committee, University of Dundee, which assisted with some travel.

\section{Notes}

1. The badscience bloggers formed a loose network out of commentators (including the authors) on the website and later webforum of U.K. science writer Ben Goldacre from around 2007 onwards, many of whom maintained their own blogs. As we describe in our previous work (Riesch \& Mendel, 2014), this community developed a set of social norms and values that among others foregrounded both direct action for science-related causes and a whimsical, trickster-like, attitude toward engagement with each other and outsiders. The network had some striking impacts, influencing among others Green Party of England and Wales science policy and the course of the British Association of Chiropractors versus Simon Singh libel proceedings (Robbins, 2010).

2. Such play did not exclude more conventional forms of engagement with the campaign, however. The authors (and some others who were engaged in critical responses to the campaign) sought to contribute to the campaign through avenues such as participating in an online forum set up to discuss the campaign constructively and through meetings with some involved in the campaign. 


\section{References}

Anderson, A. A., Brossard, D., Scheufele, D. A., Xenos, M. A., \& Ladwig, P. (2014). The "nasty effect": Online incivility and risk perceptions of emerging technologies. Journal of Computer-Mediated Communication, 19, 373-387.

Bakhtin, M. M. (1984). Rabelais and his world. Bloomington: Indiana University Press.

Bassil-Morozow, H. (2015). The trickster and the system: Identity and agency in contemporary society. New York, NY: Routledge.

Coleman, G. (2014). Hacker, hoaxer, whistleblower, spy: The many faces of anonymous. London, England: Verso.

Deleuze, G., \& Guattari, F. (1988). A thousand plateaus: Capitalism and schizophrenia (Trans. B. Massumi). London, England: Athlone.

Hayton, J. (2010). Nano-medics of the future: So what? 10minus9. Retrieved from https://10minus9.wordpress.com/2010/01/19/nano-medics-of-the-future-sowhat/

Holmes, A., \& Mendel, J. (2010). Science sidelined in the government-PR-media frenzy. Guardian Science Blog. Retrieved from https:/www.theguardian.com/ science/blog/2010/sep/07/science-future-jobs-research

Irwin, A. (2014). From deficit to democracy (re-visited). Public Understanding of Science, 23, 71-76.

Massumi, B. (1988). Translator's foreword: Pleasures of philosophy. In G. Deleuze \& F. Guattari (Eds.), A thousand plateaus: Capitalism and schizophrenia (pp. ix-xv). London, England: Athlone.

Mendel, J. (2014). Bad research and high impact: The science: So what campaign and social media criticism. ACME, 13(1), 56-61.

Mendel, J., \& Holmes, A. (2010, June). Research: So what? PR-based research, science communication and the waste of $£ 1.85 \mathrm{~m}$. Times Science Blog. Retrieved from https://web.archive.org/web/20100704031037/http://timesonline.typepad. com/science/2010/06/research-so-what-prbased-research-science-communication-and-the-waste-of- $185 \mathrm{~m}$.html

Mendel, J., \& Riesch, H. (2015). Science blogging below-the-line: A progressive sense of place? In S. Mains, J. Cupples \& C. Lukinbeal (Eds.), Mediated geographies/geographies of media (pp. 243-256). Dordrecht, Netherlands: Springer.

Morello, L. (2015). We can \# it. Nature, 547, 148-151.

Nisbet, M. C., \& Scheufele, D. A. (2009). What's next for science communication? Promising directions and lingering distractions. American Journal of Botany, 96, 1767-1778.

Plato. (n.d.). Apology (Trans. B. Jowett). Cambridge: Massachusetts Institute of Technology. Retrieved from http://classics.mit.edu/Plato/apology.html

Phillips, W. (2015). This is why we can't have nice things: Mapping the relationship between online trolling and mainstream culture. Cambridge: MIT Press.

Phillips, W., \& Milner, R. M. (2017). The ambivalent internet: Mischief, oddity and antagonism online. Cambridge, England: Polity Press. 
Riesch, H., \& Mendel, J. (2014). Science blogging: Networks, boundaries and limitations. Science as Culture, 23(1), 51-72.

Robbins, M. (2010). Furious backlash from Simon Singh libel case puts chiropractors on ropes. The Lay Scientist. Retrieved from https://www.theguardian.com/science/2010/mar/01/simon-singh-libel-case-chiropractors

Rose, H., \& Rose, S. (1972). The radicalisation of science. Socialist Register, 9, 105132.

Walsh, L. (2015). The double-edged sword of popularization: The role of science communication research in the popsci.com comment shutoff. Science Communication, 37, 658-669.

Weaver, S., \& Mora, R. A. (2016). Introduction: Tricksters, humour and activism. International Journal of Cultural Studies, 19, 479-485.

Žižek, S. (2012). Organs without bodies: On Deleuze and consequences. London, England: Routledge.

\section{Author Biographies}

Jonathan Mendel is a lecturer in human geography at the University of Dundee. His research focuses on networks, conflict, policing, security, and policy. His recent work has looked at science blogging, human trafficking and online networks, police reform, and evidence, policy, and trials.

Hauke Riesch is a lecturer in sociology at the Department of Social Sciences, Media \& Communications at Brunel University, London. He has a PhD in science and technology studies and has specialized on the public understanding of science, environmental policy, and risk. He is currently interested in citizen science, science blogs, and representations of science in popular culture, especially in comedy. 